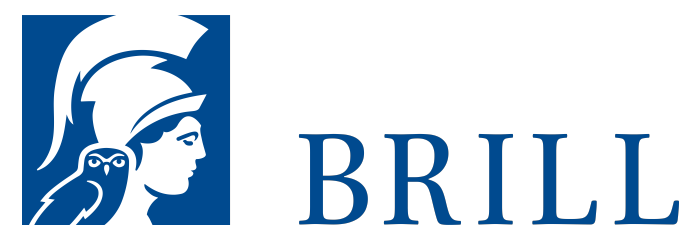

\title{
Spielend lerne ich!
}

Wie Sie Ihr Kind spielerisch fördern

Author: Michaela Grubbauer

Das Spielen von Kindern ist mehr als Zeitvertreib! Durch Spielen lernen Kinder und entdecken so sich und ihre Welt. Ergebnisse aus der Forschung belegen, dass sich frühkindliche Förderung positiv auf den Schulerfolg auswirkt.

Aber wie können Sie Ihr Kind von Anfang an in seiner Entwicklung optimal unterstützen, ohne es dabei zu überfordern? Dieser HELP-Band begleitet Sie und Ihr Kind in den ersten Lebensjahren bis zum Grundschulalter, damit eine um-fassende Förderung gelingt. Dabei steht das Spiel als wichtigste Beschäftigung im Mittelpunkt.

Mit einfachen Spielen sollen Kinder ihrem Alter entsprechend gefördert werden. Nach Altersstufen gegliederte Kapitel führen zunächst in die kindliche Entwicklung ein und präsentieren konkrete Spielanleitungen zur Förderung von Motorik, Sprache, Sozialverhalten, Kreativität und Wahrnehmungsfähigkeit. Viele nützliche Tipps für den Alltag und ein lockeres, farbiges Layout runden den Band ab.

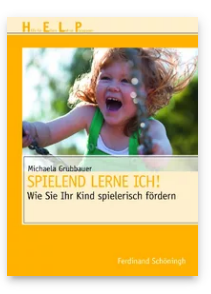

Pages: 112 Seiten

Language:

German

Subjects:

General,

Education

Publisher: Brill |

Schöningh

E-Book (PDF)

Released online:

3o Dec 2019

ISBN: $978-3^{-}$

657-77197-4

List price 
Michaela Grubbauer, Mag. phil., schloss 2009 ihr Studium der Psychoanalytischen Erziehungswissenschaft an der LeopoldFranzens-Univ. Innsbruck mit Auszeichnung ab. In der Praxis engagiert sie sich für ganzheitlich, spielorientierte Erziehungskonzeptionen sowie für flexible Erziehungshilfe.

For more information see brill.com

Order information: Order online at brill.com +44330333 0049 | customerservices@brill.com Submission information: brill.com/authors

Titles published by Brill | Fink, Brill | mentis or Brill | Schöningh: +49(o)71 5413279216 | brill@brocom.de 